\title{
Agro-ecosystem Model AGROTOOL Coupled with GIS for Simulation of the Spatial Variability of the Soil Hydrophysical Properties
}

\author{
Vladimir Badenko, Vitaly Terleev, Nikolay Arefiev, Julia Volkova, Olga Nikonova \\ Department of Water-economic and hydroengineering construction, \\ St.Petersburg State Polytechnical University, \\ 195251, St.Petersburg, Polytechnicheskaya, 29, Russia.
}

\begin{abstract}
The approach to taking into account the spatial variability of soil properties during decision making in agroecosystem management has presented. The approach is based on the quantitative indicators of plants production process (wheat crop) obtained by using a dynamic model of the agricultural plants production process AGROTOOL. The studies were conducted in the environment of a special software package that is based on the integration of the dynamic model AGROTOOL and GIS. Computer simulations data allowed identifying the conditions under which the influence of the soil hydrophysical characteristics variability on the crop production exists or disappears.
\end{abstract}

Keywords-agro-ecosystem; GIS; production process modeling; soil hydrophysical properties; soil water retention

\section{INTRODUCTION}

In agricultural land, understanding the controls on soil moisture variation can improve precision fertilizer, manure and crop yield management [1-3]. Identification and prediction of soil moisture controls at different scales thus remain important in a wide range of agronomic, hydrological, and environmental studies [4-6]. Understanding and characterizing spatio-temporal variability of soil water content presents one of the major challenges in modern soil physics [4, 7-9]. Spatial variability of soil water content was interpreted using several modeling approaches that accounted for spatial variability in soil hydrophysical properties and precipitation [3, 10-12]. Both local controls, such as vertical dominant fluxes governed by soil hydraulic properties and vegetation, and non-local controls, such as lateral processes induced by topography or climate variability, affect spatio-temporal fields of soil water contents [13]. In this context, the inclusion of spatial variability of hydrophysical parameters in the information support management decision-making systems with GIS technology for agricultural landscapes is an actual task [3, $14,15]$.

Development of approaches taking into account spatial variability of hydrophysical properties of soils during plants production process simulation (wheat crop) using the AGROTOOL model [16] in order to decision making support in practical adaptive landscape agriculture is the aim of this work.

To research the impact of spatial variability of soil properties on yield process a special information- analytical system has been developed. It consists of a GIS coupled with AGROTOOL for soil hydrophysical properties modeling software package developed also has been included in the system [8].

\section{EXPERIMENTAL DATA}

The studies were conducted on the basis of GIS database, which describes the agriculture landscape of Menkovo Experimental Station of Agrophysical Research Institute, located in the Leningrad region. Results of mathematical modeling for the yield production process of wheat on the field of 3 hectares have presented. In order to determine the values of hydrophysical soil properties of this field and to create the GIS database six soil profiles were developed on a $1 \mathrm{~m}$ depth to take soil samples (of three texture classes) from all genetic horizons of the soil profile (see Figure 1).

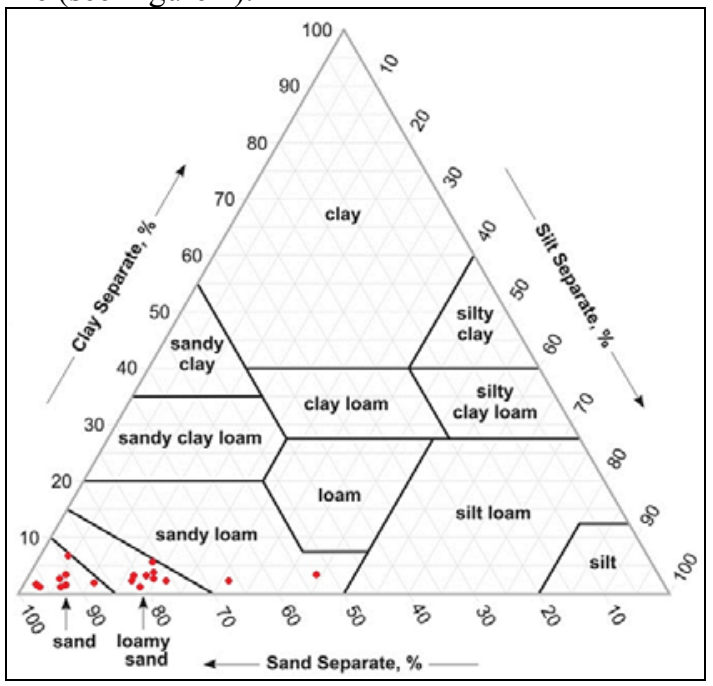

Figure 1. Textural characteristics of selected 18 soil samples

In every of these horizons experimental studies following indicators of soil needed for the modeling with AGROTOOL were determined: soil hydrological constants (hygroscopic water content, wilting point, field capacity and porosity), bulk density, solid particles density and saturated hydraulic conductivity of soil. These data allow us to conduct a fully simulation the water retention curve [8, 16-19]. 
To select the sampling points GIS technology is used. Some results of laboratory studies of the samples are shown in the Table I. These data were obtained on a pneumatic press (Soilmoisture Model 1000 Pressure Membrane Extractor, 15 bar). Sample points are shown on Figure 2. For the research in the GIS database square parcels of 0.125 ha areas were formed. The attributes of these objects were calculated from data from a table 1 with a resolution of $10 \mathrm{~cm}$ in the soil profile (vertical direction) to the depth of $1 \mathrm{~m}$. On Fig.2 the objects of simulation and their centroids, the sample points designated with 30-35 (see Table I) are shown.

TABLE I. EXPERIMENTAL DATA ON HYDROPHYSICAL PROPERTIES OF SOILS

\begin{tabular}{|c|c|c|c|c|c|c|c|}
\hline \multirow{2}{*}{ Sample points } & \multirow{2}{*}{$\begin{array}{c}\text { Layer } \\
\text { (top-bottom), } \mathrm{cm}\end{array}$} & \multicolumn{6}{|c|}{$\begin{array}{l}\text { Volumetric soil water content }\left(\mathrm{cm}^{3} \cdot \mathrm{cm}^{-3}\right) \\
\text { for different pressure }\end{array}$} \\
\hline & & $0.0 \mathrm{bar}$ & 0.15 bar & $1.2 \mathrm{bar}$ & 0.33 bar & 4.1 bar & 15 bar \\
\hline \multirow{3}{*}{31} & $A(0-24)$ & 0.443 & 0.339 & 0.253 & 0.308 & 0.136 & 0.233 \\
\hline & A2B (24-48) & 0.367 & 0.207 & 0.079 & 0.149 & 0.058 & 0.056 \\
\hline & B1 $(48-\ldots)$ & 0.382 & 0.183 & 0.085 & 0.128 & 0.063 & 0.084 \\
\hline \multirow{3}{*}{32} & $A(0-32)$ & 0.513 & 0.310 & 0.199 & 0.262 & 0.127 & 0.126 \\
\hline & A2B (32-53) & 0.402 & 0.281 & 0.163 & 0.229 & 0.124 & 0.099 \\
\hline & $B(53-\ldots)$ & 0.363 & 0.135 & 0.070 & 0.086 & 0.065 & 0.061 \\
\hline \multirow{3}{*}{33} & $A(0-36)$ & 0.523 & 0.372 & 0.283 & 0.319 & 0.170 & 0.158 \\
\hline & A2B (36-57) & 0.393 & 0.288 & 0.178 & 0.243 & 0.121 & 0.094 \\
\hline & $\mathrm{B}(57-\ldots)$ & 0.396 & 0.342 & 0.169 & 0.299 & 0.121 & 0.072 \\
\hline \multirow{3}{*}{34} & $\mathrm{~A}(0-28)$ & 0.471 & 0.340 & 0.208 & 0.282 & 0.159 & 0.148 \\
\hline & A2B $(28-55)$ & 0.342 & 0.236 & 0.140 & 0.193 & 0.113 & 0.068 \\
\hline & $\mathrm{B}(55-\ldots)$ & 0.309 & 0.221 & 0.203 & 0.208 & 0.187 & 0.155 \\
\hline \multirow{3}{*}{35} & $A(0-23)$ & 0.458 & 0.275 & 0.190 & 0.247 & 0.147 & 0.129 \\
\hline & A2B (23-43) & 0.415 & 0.216 & 0.123 & 0.212 & 0.072 & 0.052 \\
\hline & B $(43-\ldots)$ & 0.365 & 0.114 & 0.047 & 0.097 & 0.043 & 0.032 \\
\hline \multirow{3}{*}{30} & $A(0-24)$ & 0.475 & 0.301 & 0.214 & 0.283 & 0.138 & 0.123 \\
\hline & A2B (24-49) & 0.353 & 0.219 & 0.146 & 0.231 & 0.088 & 0.064 \\
\hline & B $(49-\ldots)$ & 0.344 & 0.112 & 0.118 & 0.114 & 0.051 & 0.033 \\
\hline
\end{tabular}

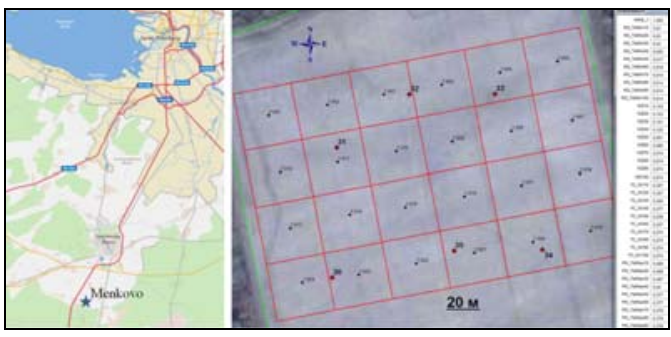

Figure 2. Menkovo Experimental Station near Saint-Petersburg (on the left); separation of the test field on relatively homogeneous square parcels of 0.125 hectares and sampling points (numbers $30-35$ ) (on the right)

On Figure 3 it can be seen thematic maps shown a content of the GIS database. Figure 3 presents a data analysis in GIS on hydrophysical soil properties of the test field which demonstrates the variability of these properties. As the main indicator of the interest for a crop production a range of available moisture was chosen. The variability of this index from 0.11 to $0.17 \mathrm{~cm}^{3} \cdot \mathrm{cm}^{-3}$ can be seen. In this case, the maximum values are achieved in different layers of the soil profile and in different parts of the field. According Figure 3, substantial variability of hydrophysical properties of the soil on the experimental field has been discovered.

\section{RESULTS AND DISCUSSION}

As a result of the simulation experiments it was found that the degree of hydrophysical soil properties variability horizontal and vertical directions was significantly affected by weather conditions, in particular precipitations. The simulation experiments were conducted for the period 2007-2013 with the spring wheat. The results show that the variability of yield and wheat phenological phases was only observed in 2008 and 2011 years. For example, the variability in the phases of the development for these years was more than 5 days, whereas for the other years the variability of yield and the phases were not observed (see Figure 4). 


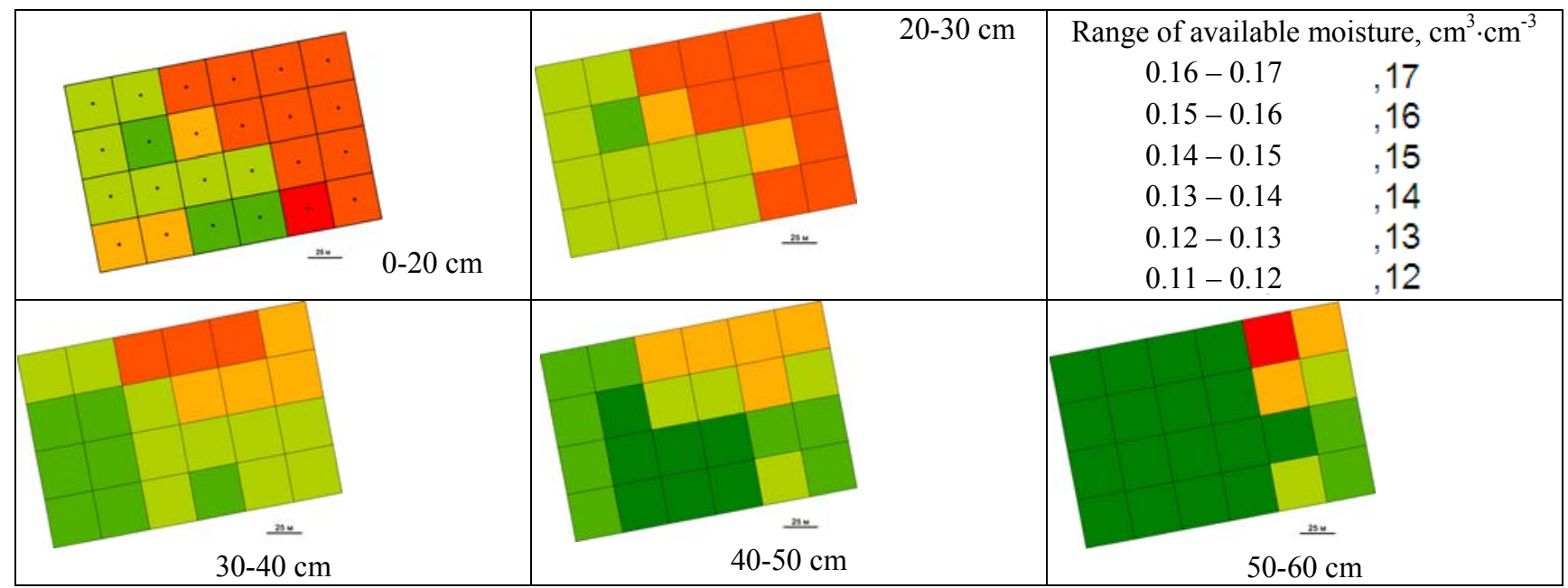

Figure 3. Variability of soil properties for different soil depth

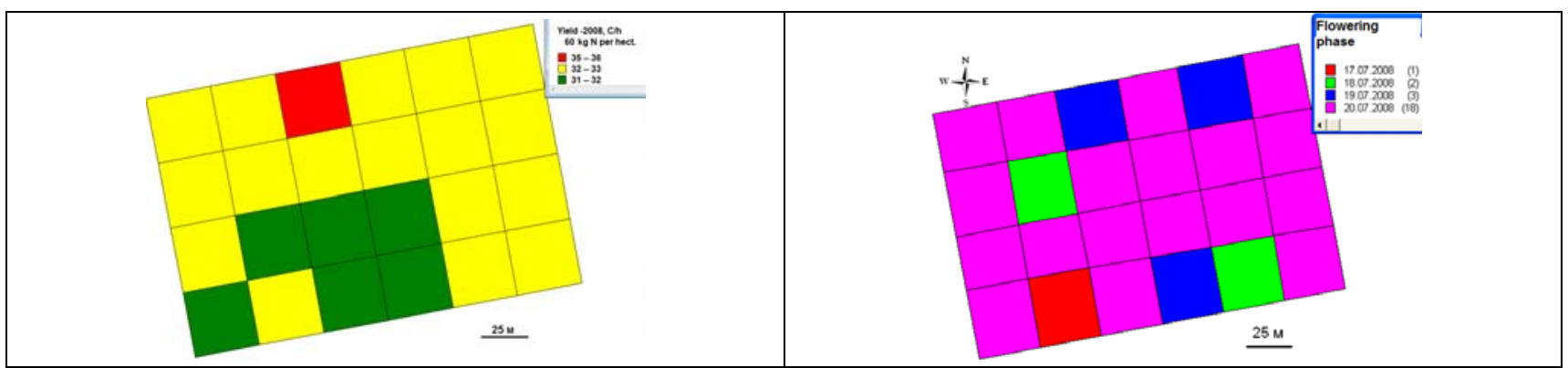

Figure 4. Spatial variation of yield process of wheat in 2008 , nitrogen fertilizer rate of $60 \mathrm{~kg} \cdot \mathrm{ha}^{-1}$ (yield and flowering phase)

An explanation for this fact can be offered on the base of an analysis of the dynamics of soil moisture in the first meter of soil, which is one of the simulation results in AGROTOOL and is determined for each day of the growing season. Specific weather conditions have created favourable moisture reserve in the first meter of soil in 2007, 2009 and 2010. In 2008 the dynamics of soil moisture during the growing season has a characteristic dome shape with a concave bottom, which is unfavourable for wheat yield process and increases the effect of the variability of hydrophysical characteristics. In 2010 the dynamics of the curve of soil moisture has a bulge up on the contrary, which is favourable for wheat yield process and eliminates the effect of the variability of soil hydrophysical properties.

\section{CONCLUSIONS}

The paper presents the methodological approach to accounting the spatial variability of hydrophysical soils properties. The information-analytical system consisting of a GIS and simulation model AGROTOOL had been developed. The system allows carrying out computer experiments to reveal an impact of the spatial variability of hydrophysical soils properties on crop yield. The computer experiments data have demonstrated that the dynamics of soil moisture during whole vegetation period plays a key role in the impact degree. The examples give evidence of the approach efficiency.

\section{REFERENCES}

[1] Zhu, Q. \& Lin, H. Influences of soil, terrain, and crop growth on soil moisture variation from transect to farm scales. Geoderma, 163, pp.45-54,2011.

[2] Schmidt, J.P., Hong, N., Dellinger, A., Beegle, D.B. \& Lin, H.S. Hillslope variability in corn response to nitrogen linked to inseason soil moisture redistribution. Agronomy Journal, 99, pp.229$237,2007$.

[3] Kar, G., Singh, R. \& Verma, H.N. Spatial variability studies of soil hydro-physical properties using GIS for sustainable crop planning of a watershed of eastern India and its testing in a rainfed rice area. Australian Journal of Soil Research, 42(4), pp.369-379,2004.

[4] Martinez, G., Pachepsky, Y.A., Vereecken, H., Hardelauf, H., Herbst, M. \& Vanderlinden, K. Modeling local control effects on the temporal stability of soil water content. Journal of Hydrology, 481, pp.106-118,2013.

[5] Williams, A.G., Ternan, J.L., Fitzjohn, C., de Alba, S. \& PerezGonzalez, A. Soil moisture variability and land use in a seasonally arid environment. Hydrological Process, 17, pp.225-235,2003.

[6] Moret-Fernandez, D., Pueyo, Y., Bueno, C.G. \& Alados, C.L. Hydro-physical responses of gypseous and non-gypseous soils to livestock grazing in a semi-arid region of NE Spain. Agricultural Water Management, 98, pp.1822-1827,2011.

[7] Pan, F., Pachepsky, Y., Jacques, D., Guber, A. \& Hill, R. Data assimilation with soil water content sensor and pedotransfer 
function in soil water flow modelling. Soil Science Society of America Journal, 76, pp.829-844,2012.

[8] Terleev, V.V., Mirschel, W., Schindler, U. \& Wenkel, K.-O. Estimation of soil water retention curve using some agrophysical characteristics and Voronin's empirical dependence. International Agrophysics, 24(4), pp.381-387,2010.

[9] Martinez-Fernandez, J. \& Ceballos, A. Temporal stability of soil moisture in a large-field experiment in Spain. Soil Science Society of America Journal, 67, pp.1647-1656,2003.

[10] Dexter, A.R. \& Bird, N.R.A. Methods for predicting optimum and the range of water contents for tillage based on water retention curve. Soil and Tillage Research, 57, pp.203-212,2001.

[11] Gerke, H.H. \& van Genuchten, M.T. A dual-porosity model for simulating the preferential movement of water and solutes in structured porous media. Water Resources Research, 29, pp.305319,1993 .

[12] Hudson, B.D. Soil organic matter and available water capacity. Journal of Soil and Water Conservation, 49 (2), pp.189-194,1994.

[13] Grayson, R.B., Western, A.W., Chiew, F.H.S. \& Blöschl, G. Preferred states in spatial soil moisture patterns: local and non local controls. Water Resources Research, 33, pp.2897-2908,1997.
[14] Aref'ev, N.V., Badenko, V.L. \& Osipov, G.K. Basin-landscape approach to the organization of environmental monitoring of hydropower complexes on the basis of geographical information technologies. Power Technology \& Engineering, 32(11), pp.660663,1998 .

[15] Kurtener, D. \& Badenko, V. GIS fuzzy algorithm for estimating the quality of soil parameter evaluation of attribute data quality. Geomatics Info Magazine, 15(3), pp.76-79,2001.

[16] Poluektov, R.A., Fintushal, S.M., Oparina, I.V., Shatskikh, D.V., Terleev, V.V. \& Zakharova E.T. AGROTOOL - a system for crop simulation. Archives of Agronomy and Soil Science $=$ Archiv fuer Acker- und Pflanzenbau und Bodenkunde, 48(6), pp.609-635,2002.

[17] Poluektov, R.A. \& Terleev, V.V. Modeling of the water retention capacity and differential moisture capacity of soil. Russian Meteorology and Hydrology, 11, pp.70-75,2002.

[18] Poluektov, R.A., Oparina, I.V. \& Terleev, V.V. Three methods for calculating soil water dynamics. Russian Meteorology and Hydrology, 11, pp.61-67,2003.

[19] Poluektov, R.A. \& Terleev V.V. Modeling the moisture retention capacity of soil with agricultural and hydrological characteristics. Russian Meteorology and Hydrology, 12, pp.73-77,2005. 